\title{
DEL «ÁNGEL DEL HOGAR» AL «ÁNGEL DEL AYUNTAMIENTO». MUJERES E IMAGEN DEL PODER EN ALICANTE (1923-1931)
}

\begin{abstract}
ADRIANA CASES SOLA
Universidad de Alicante

Recibido: 25/10/2010

Aceptado: 7/11/2010

\section{Resumen}

Este artículo realiza una interpretación de la construcción simbólica del poder de las mujeres en Alicante durante la dictadura de Primo de Rivera. En los años veinte se da un cambio en los discursos de género y se pasa del arquetipo femenino del «ángel del hogar» al de la «nueva mujer moderna». Esto, unido al proyecto regeneracionista del régimen primorriverista y al modelo de ciudadanía femenina basado en el discurso de la complementariedad de los sexos, propiciará el acceso al poder político de las mujeres. En Alicante tres mujeres entraron a formar parte del ayuntamiento. Nuestro objetivo es analizar la representación pública del poder de estas mujeres a través del estudio de tres elementos: las condiciones de su acceso al poder político, la labor que desempeñaron y los discursos que se generaron en torno a estas dos variables.
\end{abstract}

Palabras clave: Mujeres, imagen del poder, dictadura de Primo de Rivera, Alicante.

\begin{abstract}
This paper offers an interpretation of the symbolic construction of the power of women in Alicante during Primo de Rivera's dictatorship. In the 1920s gender discourses were changing. The female archetype of the «angel in the house» was changed for the «new modern woman». This transformation, the regenerationist project of Primo de Rivera's government and the extension of a female type of citizenship based on the complementarity of the sexes let the women access to political power. Three women took part in Alicante's Council. Our objective is to analyze the public representation of the power of these women by means of the study of three elements: conditions of their
\end{abstract}

Feminismo/s 16, diciembre 2010, pp. 139-158 
access to political power, their work in the council and discourses that were generated around both fields.

Keywords: Women, Power's image, Primo de Rivera's dictatorship, Alicante.

Feminismo/s 16, diciembre 2010, pp. 139-158 


\section{Introducción}

Para poder hacer un análisis sobre la representación pública del poder desde una perspectiva de género, debemos prestar atención al proceso de formación de la ciudadanía de las mujeres. La construcción de la ciudadanía femenina está estrechamente relacionada con la evolución del ideal de feminidad en la sociedad contemporánea, puesto que las características del modelo de mujer tradicional fueron la base de la exclusión de la ciudadanía de las mujeres.

En el siglo XIX la identidad femenina y la masculina se formaron a partir de funciones y cualidades diferenciadas y contrapuestas, consideradas como naturales y consustanciales al sexo, y por lo tanto, inmutables. Por lo que cada sexo ocupó un espacio distinto en función de sus rasgos «naturales». La esfera pública, lugar en el que se desarrollaría la ciudadanía política, se vinculó por naturaleza a la identidad masculina, y la esfera privada, en la que se desarrollaría la vida familiar, lo hizo a la femenina ${ }^{1}$.

Sin embargo, había una contradicción entre los ideales de igualdad y libertad en los que se fundamentaban los movimientos liberales y la exclusión de las mujeres de la ciudadanía. Pero si se partía de la base de que las mujeres no eran iguales a los hombres por su naturaleza diferenciada que además les hacía ser seres inferiores intelectual y físicamente y, por lo tanto, dependientes de los hombres, no tenían por qué tener derecho a ser ciudadanas porque «no podía haber igualdad entre quienes no son iguales $»^{2}$. De este modo se formó el discurso de la domesticidad que reducía el campo de acción de las mujeres al hogar y sus funciones a la dedicación a la familia.

En las primeras décadas del siglo Xx y sobre todo, a partir de la Primera Guerra Mundial, el modelo de feminidad empezó a cambiar. El trabajo

1. Bastantes investigaciones en historia de género han prestado atención a la construcción de la identidad femenina y a la relación entre mujeres y ciudadanía en la sociedad contemporánea. Destacamos, entre otras: GÓMEZ-FERRER, Guadalupe. «Hacia una redefinición de la identidad femenina: las primeras décadas del siglo XX». Cuadernos de Historia Contemporánea, 24 (2004), pp. 9-22; FraISSE, Geneviève. Los dos gobiernos: la familia y la ciudad. Madrid, Cátedra (Feminismos), 2003.

2. Aguado, Ana. «Ciudadanía, mujeres y democracia». Historia Constitucional, 6 (2005), pp. 11-27.

Feminismo/s 16, diciembre 2010, pp. 139-158 
realizado por muchas mujeres durante la guerra, que ocuparon puestos tradicionalmente masculinos y la organización de los movimientos feministas que reclamaron el acceso de las mujeres a la ciudadanía son dos factores que abren el camino hacia una nueva consideración social de las mujeres. En los años veinte se dio un cambio de actitud en los discursos de género. La percepción del feminismo como una amenaza a la estructura social existente que descansaba sobre la familia patriarcal y sobre la separación sexual de los espacios fue entendida desde algunos sectores como una reacción defensiva lógica de las mujeres ante la situación de desigualdad y subordinación en la que vivían, y así lo interpretaron en el diario monárquico conservador El Tiempo:

[...] justo y lógico es que [las mujeres] huyan del hogar y se defiendan [...] En el foro, en el libro, en las aulas, en los Municipios, las mujeres van ganando puestos [...] y esto no por un capricho de ellas, sino porque tienen necesidad de acudir [a ellos] no sólo para ganarse la subsistencia, sino para defender sus derechos, que los hombres no quisieron ni supieron defender ${ }^{3}$.

Por eso se intentó buscar soluciones a los problemas que surgieron en las relaciones entre mujeres y hombres aceptando avances moderados para poder conservar la estructura vigente sin trasgredir demasiado los roles de género tradicionales ${ }^{4}$. Se pasó del arquetipo femenino del «ángel del hogar» al de «nueva mujer moderna» que asumía un perfil profesional para las mujeres solteras pero seguía manteniendo el modelo de feminidad que definía la maternidad y el matrimonio como destino deseado o primordial ${ }^{5}$.

Por lo tanto, se cedía una pequeña porción para poder conservar el núcleo principal: la restricción de la ciudadanía política y social a las mujeres casadas. Estas resistencias a la plena incorporación a la ciudadanía de las mujeres en términos de igualdad propiciaron el surgimiento de algunos movimientos de mujeres que empezaron a defender el discurso de la complementariedad de los sexos como base de su proyecto político: las cualidades femeninas defendidas por este discurso dotaban a las mujeres de ciertos valores que las hacía

3. «Masculinismo y feminismo», El Tiempo, 13-VI-1926.

4. ARESTI, Nerea. Médicos, donjuanes y mujeres modernas. Los ideales de feminidad y masculinidad en el primer tercio del siglo XX. Bilbao, Servicio Editorial de la Universidad del País Vasco, 2001.

5. NASH, Mary. Mujeres en el mundo. Historia, retos y movimientos. Madrid, Alianza, 2004, pp. 58-62; CAPEL, Rosa María. «El modelo de mujer en España a comienzos del siglo XX», en V. Maquieira D’Angelo, G. Gómez-Ferrer Morant y M. Ortega López (eds.). Mujeres y hombres en la formación del Pensamiento Occidental. Actas de las VII Jornadas de Investigación Interdisciplinaria. vol. II, Madrid, Instituto Universitario de Estudios de la Mujer, Universidad Autónoma de Madrid, 1989, pp. 311-320. 
moralmente superiores a los hombres y por lo tanto, más competentes que ellos en políticas sociales ${ }^{6}$.

Estas teorías, unidas a la crisis política de la Restauración y al discurso regeneracionista de Primo de Rivera, formaron los cimientos de la participación política femenina durante el régimen dictatorial y sirvieron de base para la construcción de una determinada imagen de las mujeres en el poder.

La crisis de la Restauración trajo consigo una crisis política y social pero también una crisis de identidad nacional y de identidad de género. El auge que tuvo el feminismo tras la Primera Guerra Mundial, el proceso de transición que estaba teniendo lugar en Europa de un sistema político restringido a uno más abierto a la participación de los diversos grupos sociales, y la elaboración de proyectos regeneracionistas nacionales, crearon un ambiente propicio a la participación política de aquellas mujeres que construyeron un modelo de ciudadanía femenina sobre los cimientos de la diferencia sexual.

Así, durante la dictadura de Primo de Rivera, la coincidencia entre el programa de regeneración política del régimen y el modelo de ciudadanía propuesto por las militantes feministas basado en el maternalismo social permitió que por primera vez las mujeres accedieran a la vida política. Y aunque los derechos conseguidos por las mujeres durante la dictadura fueron considerados por una gran parte de la opinión pública como una concesión masculina fruto de la galantería, y a pesar de la actitud paternalista del régimen, lo cierto es que estas políticas supusieron un paso más, entre otros, hacia la consecución de una ciudadanía política femenina integral.

El acceso de las mujeres al poder político arrancó con la publicación del Estatuto Municipal de 1924. Gracias a él algunas mujeres ocuparon los puestos de concejalas, tenientes de alcalde y alcaldesas en varios municipios del estado español. Los trabajos de Gloria Franco ${ }^{7}$ y Pilar Folguera ${ }^{8}$ nos acercan a las figuras de estas políticas, a los discursos que se generaron en torno a ellas, a los debates sobre la conveniencia o no de que las mujeres asumieran labores

6. NASH, Mary. Op. cit., pp. 134-136; de la misma autora: «Identidades de género, mecanismos de subalternidad y procesos de emancipación femenina». Revista CIDOB d'Afers Internacionals, 73-74 (2006), pp. 39-57.

7. FRANCO RUBIO, Gloria Ángeles. «La contribución de la mujer española a la política contemporánea: de la Restauración a la Guerra Civil (1876-1939)». En R. M. Capel Martínez (coord.). Mujer y sociedad en España (1700-1975). Madrid, Ministerio de Cultura, Instituto de la Mujer, 1986, pp. 239-263.

8. Folguera CRESPO, Pilar. «Revolución y Restauración. La emergencia de los primeros ideales emancipadores (1868-1931)». En E. Garrido (ed.). Historia de las mujeres en España. Madrid, Síntesis, 1997, pp. 451-492. 
de gobierno, y a las causas que llevaron a las autoridades a aprobar estos derechos políticos para las mujeres.

La participación política de las mujeres en los años veinte y su relación con el catolicismo social ha sido estudiada recientemente por Inmaculada Blasco y Rebeca Arce, entre otras, que ponen de manifiesto que el movimiento católico, lejos de suponer una rémora para la movilización política de las mujeres, favoreció su organización y puesta en práctica como instrumento dentro de su programa de recristianización de la sociedad ${ }^{9}$. Un elemento que, si por un lado ayudó al acceso de algunas mujeres a la política, por otro lado supuso un factor más para consolidar el estereotipo de la mujer beata y conservadora que servirá de argumento a aquellos sectores progresistas contrarios al sufragio femenino que desarrollaron un antifeminismo de base anticlerical ${ }^{10}$.

Otros trabajos también proponen un análisis de la participación femenina en los organismos políticos durante la dictadura de Primo de Rivera y su significación en el proceso de construcción de la ciudadanía femenina por un lado ${ }^{11}$, y de los discursos referentes a esta participación y al modelo ideal de feminidad, por otro ${ }^{12}$. Sin embargo, la mayoría de investigaciones sobre la participación política femenina durante la dictadura son de carácter general y faltan estudios locales. Como excepción, debemos mencionar el trabajo que está desarrollando el grupo de investigación de la Universidad Complutense de Madrid «Relaciones de género en el mundo contemporáneo: una

9. Blasco Herranz, Inmaculada. "Tenemos las armas de nuestra fe y de nuestro amor y patriotismo; pero nos falta algo'. La Acción Católica de la Mujer y la participación política en la España del primer tercio del siglo XX». Historia Social, 44 (2002), pp. 3-20; de la misma autora «Ciudadanía y militancia católica femenina en la España de los años veinte». Ayer, 57 (2005), pp. 223-246; y Paradojas de la ortodoxia. Políticas de masas y militancia católica en España (1919-1939). Zaragoza, Prensas Universitarias de Zaragoza, 2003; ARCE PINEDO, Rebeca. «De la mujer social a la mujer azul: la reconstrucción de la feminidad por las derechas españolas durante el primer tercio del siglo XX». Ayer, 57 (2005), pp. 247-272; y también Dios, patria y hogar. La construcción social de la mujer española por el catolicismo y las derechas en el primer tercio del siglo XX. Santander, PubliCan, Ediciones de la Universidad de Cantabria, 2007.

10. SAlOmón CHÉLIZ, $M^{a}$ del Pilar. «Beatas sojuzgadas por el clero: la imagen de las mujeres en el discurso anticlerical en la España del primer tercio del siglo XX». Feminismo/s, 2 (2003), pp. 41-58.

11. Díaz Fernández, Paloma. «La dictadura de Primo de Rivera. Una oportunidad para la mujer». Espacio, Tiempo y Forma, Serie V, H ${ }^{a}$ Contemporánea, 17 (2005), pp. 175-190.

12. GonZÁlez CASTILlejo, $\mathrm{M}^{\mathrm{a}}$ José. «Entre lo público y lo privado: mujeres y ciudadanía durante la Dictadura de Primo de Rivera». En C. Campos Luque y M.J. González Castillejo (coords.). Mujeres y dictaduras en Europa y América: el largo camino. Málaga, Universidad de Málaga, 1996, pp. 49-74. 
perspectiva interdisciplinar desde la Historia, la Geografía y el Derecho» ${ }^{13}$, que está estudiando la presencia de las mujeres en los poderes locales y sus características en la realidad española desde la dictadura de Primo de Rivera hasta la actualidad ${ }^{14}$. En la misma línea, el objetivo principal de este trabajo es realizar para la ciudad de Alicante, que contó durante la dictadura con tres concejalas, un análisis sobre la labor que desempeñaron, así como la relación entre ésta y los discursos que se generaron en torno al acceso de las mujeres a la política activa. El estudio de estos dos elementos es crucial a la hora de interpretar la construcción simbólica del poder de las mujeres y la proyección que esta imagen tiene en la sociedad del momento.

Alicante era en los años veinte una ciudad moderna, abierta a diversas corrientes de opinión y en la que el republicanismo y el socialismo tenían una gran tradición. Además era una ciudad de carácter comercial y de servicios, ya que, de la población activa, la mitad estaba ocupada en el sector terciario, que atrajo a la mayoría de las mujeres de clase media que empezaron a incorporarse al mundo del trabajo. En este contexto, veremos las percepciones entre la población alicantina ante la llegada al poder municipal de las mujeres.

\section{El acceso de las mujeres a los poderes locales}

La corrupción política en la etapa de la Restauración y la crisis por la que pasaba el país desde la pérdida de las colonias en 1898 ponían en peligro el concepto de virilidad y cuestionaba la labor de los hombres en la política dando como resultado una situación que empezó a calificarse de «naufragio de tanto valor político nacional en el que la masculinidad fué a la quiebra»y desde la que se empezó a valorar la entrada de las mujeres en política como una alternativa necesaria a este fracaso masculino. Esta postura fue mantenida por periódicos conservadores y católicos como El Día:

La mujer permanece inédita en la función gubernativa y hay derecho a esperanzar en ella. Es el factor que nos queda reservado para el trance supremo de ver fracasar definitivamente a los hombres, a los super hombres, a los prohombres...que tanto fracaso interino han experimentado ${ }^{15}$.

\footnotetext{
13. Este grupo está compuesto por Gloria Nielfa, Guadalupe Gómez-Ferrer, Ana Sabaté, Juana Rodríguez Moya, Cándida Gago, Magdalena Suárez, Rosario Franco Ruiz, Ma del Carmen Muñoz y Marta del Moral.

14. NiELFA, Gloria et alii. «El acceso de las mujeres a los poderes locales en España»: $X$ Congreso de la Asociación de Historia Contemporánea, Universidad de Cantabria, 2010 (en prensa).

15. El Día, 8-VI-1923.
}

Feminismo/s 16, diciembre 2010, pp. 139-158 
El régimen de Primo de Rivera tenía como uno de sus principales objetivos la regeneración política y administrativa. Esta situación permitió la entrada en el programa del gobierno de las militantes católicas ya que éstas defendían la acción social y política de las mujeres bajo los mismos términos que aquél.

Acción Católica de la Mujer había surgido en 1919, en el contexto del florecimiento de las asociaciones católicas en Europa y con el desarrollo del movimiento católico español, una de las primeras corrientes que fomentó la entrada de las mujeres en sus organismos, como medio para aumentar su base social y promover sus objetivos de recristianización en respuesta a las corrientes secularizadoras y laicizadoras. Las militantes de ACM, además de colaborar en esta tarea de recristianización, elaboraron una versión de la ciudadanía política femenina basada en el patriotismo nacionalista y en la identidad nacional católica, y en una diferencia de género entendida como capacidad de proyección de cualidades femeninas al espacio público ${ }^{16}$.

Este modelo de ciudadanía política femenina encajaba a la perfección con los ideales regeneracionistas del régimen de Primo de Rivera: las mujeres serían los sujetos políticos regeneradores del país. Según Pilar Folguera, la ACM estuvo detrás de las disposiciones del gobierno de Primo de Rivera sobre la participación política femenina, al menos en la elaboración del censo electoral y en las campañas de propaganda del Estatuto Municipal, que fueron funciones que la dictadura delegó en manos de esta organización ${ }^{17}$.

Entre las nuevas medidas del Directorio Militar se encontraba el Estatuto Municipal de 8 de marzo de $1924^{18}$. Este Estatuto supuso la consecución de los derechos políticos restringidos a las mujeres que tenían detrás de sí la

16. Blasco Herranz, Inmaculada. « Tenemos las armas de nuestra fe...», Op.cit., pp. 9-11; ARCE PINEDO, Rebeca. «De la mujer social a la mujer azul...», Op. cit., pp. 265-266.

17. Folguera CRESPO, Pilar. «Feminismo y Estado: la participación de la mujer en las instituciones políticas durante la dictadura de Primo de Rivera». Bulletin du Département de Recherches Hispaniques Pyrenaica, 27 (1983), pp. 32-51.

18. El Estatuto Municipal de 8 de marzo de 1924 establecía que: «Serán electores todos los españoles de veintitrés años y las españolas de igual edad que tengan carácter de cabeza de familia con casa abierta. Se entiende que la mujer es cabeza de familia, a estos efectos, cuando, viviendo con casa abierta y estando avecindada en un término municipal, no se halle sujeta a patria potestad, autoridad marital ni tutela. Para ser concejal de elección popular se exigirá ser elector, saber leer y escribir y tener veinticinco años, la mujer cabeza de familia podrá serlo reuniendo iguales condiciones». Publicado en la Gaceta de Madrid, 8-III-1924. 
lucha de las organizaciones feministas y cuatro intentos frustrados por obtener el sufragio femenino ${ }^{19}$.

Como consecuencia de las nuevas disposiciones electorales se depuró el censo dando como resultado un total de 6.783.629 electores de los que 1.729.793 eran mujeres ${ }^{20}$. Aunque se convocaron elecciones para 1925, éstas nunca se celebraron. A pesar de ello, en 1924 se renovaron los ayuntamientos entrando a formar parte de ellos muchas mujeres que ocuparon cargos de concejalas, tenientes de alcalde e incluso alcaldesas ${ }^{21}$. La primera alcaldesa de España fue Matilde Pérez Mollá, que fue designada por el gobernador civil de Alicante para gobernar el pequeño municipio de Quatretondeta, en el que había nacido. Matide Pérez Mollá pertenecía a la familia más acaudalada de la localidad y estuvo al frente de su consistorio desde octubre de 1924 hasta enero de 1930, periodo en el que impulsó la construcción de la carretera que une la población con Gorga y llevó la luz eléctrica a las calles y a los hogares del municipio, entre otras medidas 22 .

Ante la entrada de las mujeres en los ayuntamientos hubo opiniones diversas que se plasmaron en la prensa alicantina. Las voces favorables se mantenían dentro del discurso tradicional de género y de la imagen de la mujer que promovía el régimen, reflejo también del discurso de las militantes católicas, sobre todo desde las publicaciones que apoyaban la labor de la dictadura, como Diario de Alicante:

Poco a poco la mujer va conquistando plazas y cargos antes exclusivamente reservados a los hombres. La causa de esto no sólo ha sido un exacto conocimiento de sus aptitudes de las que ella misma no se había percatado antes, sino de la necesidad cada día más imperiosa de hacer frente a las luchas de la vida $[\ldots]$ El feminismo triunfa; únicamente se ha de precaver el riesgo de no poner a las mujeres en ciertos atolladeros que las lleven al fracaso, al ridículo, o que las masculinice demasiado [...] Nos parece que su delicadeza, las

19. Antecedentes próximos del Estatuto Municipal y de los debates por el sufragio femenino en Díaz FerándeZ, Paloma. Op. cit., pp. 177-179; Franco Rubio, Gloria Ángeles. Op. cit., p. 246; de la misma autora: «Los orígenes del sufragismo en España». Espacio, Tiempo y Forma, Serie V, 16 (2004), pp. 455-482; FAGOAGA, Concha. La voz y el voto de las mujeres. El sufragismo en España. 1877-1931. Barcelona, Icaria, 1985; FOLGUERA CRESPO, Pilar. «Revolución y Restauración...», Op. cit., pp. 483-484; BLASCO HerRANZ, Inmaculada. «Ciudadanía y militancia católica...», Op. cit., p. 238.

20. DíAZ FERnÁndeZ, Paloma. Op. cit., p. 180.

21. Gloria Franco incluye una relación de las concejalas y alcaldesas que entraron a formar parte de los ayuntamientos durante la dictadura de Primo de Rivera, en las que indica nombre, municipio y fecha de ingreso, y para las alcaldesas además estado civil y profesión. Pero este listado, al menos el de concejalas, está incompleto. Véase Franco RUBIO, Gloria Ángeles. «La contribución de la mujer española...», Op. cit., pp. 249 y 251.

22. «La primera alcaldesa de España», Diario de Alicante, 31-X-1924.

Feminismo/s 16, diciembre 2010, pp. 139-158 
funciones augustas que dentro del hogar está llamada a cumplir y su misma belleza y refinamiento sentimental, parece divorciarse algo, y aún mucho, de ciertos cargos y profesiones [...] Veremos cómo cumplen las nuevas concejales su cometido; no tendrán que ser unas lumbreras para ponerse al nivel y hasta superar a sus colegas varones. Si las innatas disposiciones que la mujer posee para el régimen y la administración del hogar logra trasladarlas al Municipio, desde luego podemos felicitarnos de su elección. ${ }^{23}$

Como pone de manifiesto Gloria Franco, la elección de estas mujeres para los cargos gubernativos en los municipios se hizo en función de la relación de éstas con la ideología del régimen (eran mujeres conservadoras y católicas afectas a la dictadura), por ser mujeres pertenecientes a familias con cierto prestigio social o por su proximidad a hombres que ocupaban puestos políticos o militares ${ }^{24}$. Mujeres con grandes méritos personales acreditados y pertenecientes a un estatus social privilegiado, algo que resaltan las noticias de prensa:

En Ronda, entre los concejales corporativos figura [...] la maestra Carmen Lucena, inteligentísima profesora que ha dado reiteradas pruebas de inteligencia y laboriosidad. En el Ayuntamiento de Segorbe, [...] se ha dado entrada a cuatro distinguidas señoras, entre ellas a la respetable viuda de don Celso Crespo ${ }^{25}$.

El 12 de diciembre de 1924 se renovó el Ayuntamiento de Alicante y entraron a formar parte del mismo tres mujeres: Catalina García Trejo, Cándida Jimeno Gargallo y María del Socorro Solanich Lacombe ${ }^{26}$. Las tres eran maestras y la primera era además profesora de la Escuela Normal, hermana de Juan García Trejo, Capitán General de la V Región Militar, y directora de la publicación quincenal El Magisterio de Alicante, periódico portavoz de las reivindicaciones

23. «Mujeres concejales», Diario de Alicante, 30-X-1924.

24. Franco Rubio, Gloria Ángeles. «La contribución de la mujer española...», Op. cit., pp. 249; NIELFA, Gloria et alii. Op. cit., p. 3.

25. «Si las mujeres mandasen... La gracia femenina en los Ayuntamientos», El Día, 14-IV-1924.

26. Catalina García Trejo fue elegida sexta teniente de alcalde y vocal de la Junta Provisional de Instrucción Pública; además se le asignaron la presidencia de la Comisión de Instrucción Pública y la de la Junta Local de Primera Enseñanza. Cándida Jimeno fue nombrada sustituta de teniente de alcalde, vocal de la Comisión de Instrucción Pública, de la Comisión de Beneficencia y de la Asociación Alicantina de Caridad. Y por último, María del Socorro Solanich fue suplente de concejal-jurado, vocal de la Comisión de Instrucción Pública y vocal de la Comisión Especial de Ensanche. Archivo Municipal de Alicante (AMA), Actas del Pleno del Ayuntamiento de Alicante, Libro 223, 12-XII-1924 y 20-XII-1924. 
profesionales de maestros y maestras ${ }^{27}$. Al no celebrarse elecciones, todos los cargos del ayuntamiento fueron designados directamente por el Gobernador Civil de la provincia, Cristino Bermúdez de Castro.

Al igual que en el resto de municipios españoles, en Alicante se puso a las mujeres al frente de juntas y comisiones relacionadas con las labores realizadas en el hogar (Beneficencia, Caridad, Instrucción Pública, Higiene), por lo que su actividad sería concebida como una extensión de las cualidades femeninas al espacio público ${ }^{28}$. Excepciones a esta situación general son las alcaldesas Matilde Pérez Mollá (Quatretondeta, Alicante) y Concepción Pérez Iglesias (Portas, Pontevedra), y las concejalas María López de Sagredo (Barcelona) o Victoria Quílez (Zuera, Zaragoza), también preocupadas por gestionar las comisiones de Hacienda y Obras Públicas ${ }^{29}$, además de María del Socorro Solanich, que fue vocal de la Comisión de Ensanche en el Ayuntamiento de Alicante.

Sin embargo, al margen de excepciones, la proyección de las cualidades propuestas por el ideal de feminidad tradicional era lo que se esperaba de las mujeres en los ayuntamientos y así se recibió su incorporación a los mismos. Por eso es significativa tanto la presentación de Cándida Jimeno en el Ayuntamiento de Alicante, como la acogida a las tres concejalas en el mismo por parte del concejal Navarro:

La Señorita Jimeno dirige un saludo al Señor Alcalde, a los Señores Concejales y al público que asiste a la sesión, en nombre propio y en el de sus compañeras las Señoritas García Trejo y Solanich. Dice que llega al escaño concejal que se le ha ofrecido no con satisfacción, sino con miedo, expresando que si en los momentos solemnes de su vida tuvo miedo no fue más que por su nombre y ahora lo siente y acrecentado, porque tiene conciencia de que es ella la representación de la mujer dignificada a la que por primera vez se le trae a este Ayuntamiento y además porque no pueden olvidar sus compañeras y ella que son maestras. Añade que se le requirió para venir a trabajar por Alicante y estima que a esta noble ciudad [...] no puede ella negarle su labor decidida y entusiasta. Termina pidiendo al Señor Alcalde y a los Señores

27. Esta publicación continúa la tradición de El Monitor de Magisterio o El Faro del Magisterio, publicados también en Alicante. Ver Moreno SÁEZ, Francisco (ed.). La prensa en la ciudad de Alicante durante la dictadura de Primo de Rivera (1923-1931). Alicante, Instituto de Cultura «Juan Gil-Albert», Diputación Provincial de Alicante, 1995, pp. 133-134.

28. Franco Rubio, Gloria Ángeles. «La contribución de la mujer...», Op. cit., p. 250; FOlguera CRESPO, Pilar. «Revolución y Restauración...», Op. cit., p. 488; BlASCO HERRANZ, Inmaculada. « Tenemos las armas de nuestra fe...» Op. cit., p. 6; y «Ciudadanía y militancia católica...», Op. cit., p. 224; DíAz FeRnÁndez, Paloma. Op. cit., p. 183; ARCE PINEDO, Rebeca. «De la mujer social a la mujer azul...», Op. cit., p. 259.

29. Nielfa, Gloria et alii. Op. cit., p. 4.

Feminismo/s 16, diciembre 2010, pp. 139-158 
Concejales que acepten el concurso de la mujer para cuanto sea beneficioso para este pueblo.

El señor Navarro [...] añade que así como el hombre proclamó a la mujer ángel del hogar, los Concejales desean que las distinguidas señoritas que vienen a honrarles con su colaboración, sean también aquí el ángel que a todos inspire el lema de la obra común, que debe ser y será el bien de Alicante ${ }^{30}$.

Vemos cómo aunque Jimeno era consciente de que ella y sus compañeras representaban a la «mujer dignificada» y se sentía parte de un colectivo que estaba empezando a valorar su fuerza como colectivo, demandando además respeto para su trabajo, Navarro hacía alusión a su papel como colaboradoras de los hombres y dejaba claro que solo gracias a ellos se debía su participación en política, resaltando la proyección de la figura del «ángel del hogar»al ayuntamiento.

Por lo tanto, los hombres percibían la entrada de las mujeres en los ayuntamientos como una extensión de las labores domésticas al municipio y su entrada en política como una concesión fruto de la galantería masculina y no como un logro del feminismo ${ }^{31}$. Se mantenía un discurso paternalista y condescendiente que recordaba que aunque las relaciones de género estaban en proceso de transformación, las mujeres seguían manteniendo una posición subordinada con respecto a los hombres. Por lo que permanece una percepción del ejercicio del poder por parte de las mujeres como complementario y subordinado en relación al de los hombres.

En el Ayuntamiento de Alicante, de las tres concejalas, fue Catalina García Trejo la que más activamente participó en política. Entre otras cosas, propuso varias medidas para mejorar las condiciones de las escuelas de niñas y niños de la ciudad, intervino en la concesión de contratos de arrendamiento de las casas en las que se establecían escuelas, demandó créditos para subvencionar colonias escolares, solicitó la creación de escuelas nacionales mixtas para las partidas de Monnegre, Alcoraya y Verdegás y la creación de dos escuelas en la partida del Bacarot; discutió sobre el reparto de dinero en los presupuestos del ayuntamiento; su comisión (Instrucción Pública) propuso conceder un premio a la Sociedad «Lo Rat Penat» de Valencia proponiendo el tema «Mujeres célebres del Reino de Valencia»; y acudió como representante del ayuntamiento junto con otros concejales al reparto de premios de la fundación Juan Maisonnave el 26 de julio de $1925^{32}$. Su labor le valió el reconocimiento del alcalde que declaró «que el Concejo debe profundo reconocimiento

30. AMA, Actas del Pleno del Ayuntamiento de Alicante, Libro 226, 12-XII-1924.

31. González Castillejo, Ma José. Op. cit., pp. 70-71.

32. AMA, Actas del Pleno del Ayuntamiento de Alicante, Libros 226-228. 
a la Srta. García Trejo por la brillante labor que viene realizando gracias a la cual todas las Escuelas Nacionales quedarán decorosamente instaladas». Además «propone que conste en acta un voto de gracias, acordándose así por unanimidad ${ }^{33}$. Sobre las otras dos concejalas encontramos información referente a su participación en las votaciones que se llevan a cabo en las sesiones del ayuntamiento, pero no sobre iniciativas propias.

\section{Percepciones sobre el ejercicio del poder de las mujeres}

Gloria Franco resalta la escasa información sobre la actuación de las mujeres en la política municipal aparecida en la prensa de la época ${ }^{34}$, lo cual es cierto en el caso de la prensa alicantina, en la que encontramos más artículos dedicados a los debates por el sufragio, a la idoneidad o no del acceso de las mujeres a la política y sobre la ocupación de nuevos puestos de trabajo por las mujeres, que sobre su labor en el ayuntamiento.

La mayor parte de la opinión pública seguía manteniendo la idea de que el destino primordial de todas las mujeres debía ser la maternidad. En la línea de la imagen de la mujer proyectada por el régimen y apoyada por el modelo de ciudadana basado en la diferencia sexual se inscribe el maternalismo social. Se concebía el instinto maternal como algo innato en las mujeres, una cualidad que ahora se extrapolaba al ámbito público. Por lo que hubo mujeres que construyeron su ciudadanía en torno a las cualidades femeninas diferenciadas de las masculinas e hicieron de la maternidad la fuente de la que emanaban sus derechos. Eran conscientes también de que el modelo de madre era el más valorado social y políticamente, ya que el prototipo de «mujer-madre» fue uno de los más difundidos por el discurso de la dictadura, un modelo ligado a una función biológica sinónimo de perpetuación de la raza robusta y sana ${ }^{35}$. En estos términos se expresaba Beatriz Galindo, que reclamaba derechos no como mujer o como ciudadana, sino como madre:

[...] Pero la acción femenina, una vez adquirido el instrumento político que es el sufragio, vuelve los ojos y encauza sus energías por nuevos derroteros que aseguren mejor sus derechos de ciudadana y nacional y más aún los de su descendencia, ya que el problema feminista más que reivindicación para la mujer, lo es para el niño [...] Una madre buena y hacendosa podrá garantizar el bienestar físico de una familia, pero únicamente la que, por añadidura, es

33. AMA, Actas del Pleno del Ayuntamiento de Alicante, Libro 226, 7-I-1925.

34. Franco RUBio, Gloria Ángeles. «La contribución de la mujer española...», Op. cit., p. 250.

35. GonZÁlez Castillejo, Ma José. Op. cit., pp. 50-51.

Feminismo/s 16, diciembre 2010, pp. 139-158 
culta, sabrá labrar la felicidad de los que de ella dependen, y obtener los más altos rendimientos espirituales, para el mañana ${ }^{36}$.

Y Sara Isaura defendía la labor de las mujeres en los ayuntamientos, pero manteniendo que el núcleo central de sus vidas era la familia:

[...] ¿Es ajena [la mujer] a la política y al gobierno y administración del Estado? No. En los Municipios figura dignamente y ejerciendo sus más elevados cargos, demuestra saber, habilidad, independencia del carácter y una devoción sincera por la moralidad. [...] El paso está dado. La mujer española del siglo XX deja de ser la sierva del hombre, para convertirse en compañera y asociada [... en la lucha por la vida y en el sostenimiento y sosiego del hogar. Creo que lo entenderán así las mujeres [...] puesto que su sabiduría tiene que enseñarle esta verdad; que sin hogar no hay familia, ni patria, ni felicidad ${ }^{37}$.

Por otro lado, también encontramos voces más tradicionales que seguían manteniendo que el lugar que les correspondía a las mujeres era única y exclusivamente el hogar. El prototipo de «mujer-madre» que servía por un lado para apoyar la participación política de las mujeres (la sociedad era una proyección de la familia en el ámbito público), por otro era el núcleo de las tesis sustentadas por aquellas personas contrarias a la ciudadanía política femenina: las mujeres que trabajaban fuera del hogar y participaban en política desatendían su principal labor en la vida, la de madre y esposa. María del Refugio mantiene esta idea en un artículo del diario adepto al régimen El Tercio:

Una madre feliz en su hogar, junto a la cuna de su hijo, meciéndolo suavemente y contemplando su dulce sueño. Qué le importa el ruido, el esplendor bullicioso de la sociedad, si sus hijos le encantan con sus sonrisas, con sus juegos infantiles y su dulce algarabía, si su mayor delicia es acariciarlos, vestirlos y peinar los negros o dorados rizos de su sedosa cabellera ${ }^{38}$.

Y en términos más apocalípticos se expresaban en El Tiempo, afirmando que el acceso de las mujeres a puestos tradicionalmente masculinos traería consigo el abandono de la familia por parte de éstas y por lo tanto, la desestructuración de la sociedad:

[...] La mujer moderna se aleja de la familia cada día más. Van surgiendo las doctores, las abogados, las concejales..., que poco a poco se atribuyen las facultades correspondientes al hombre [...] Cierto que algunos hombres [...] pueden sustituir a la mujer en el gobierno de la casa. Pero la influencia moral de la mujer es indiscutible [...] La mujer desaparece del hogar y éste desaparece de la sociedad ${ }^{39}$.

36. Galindo, Beatriz. «La mujer manda», Diario de Alicante, 17-VII-1925.

37. ISAURA, Sara. «La mujer española», Diario de Alicante, 15-VI-1925.

38. $\mathrm{M}^{\mathrm{a}}$ del Refugio. «Amor maternal», El Tercio, 15-VI-1929.

39. Romero-Vicient, Gregorio. El Tiempo, 24-X-1926. 
Hubo pocas reacciones en contra de la idea de que la maternidad no era solo el deber de las mujeres para ser mujeres completas, sino que era una tarea sagrada y primordial para el sostén de la sociedad, cuya base era la familia. La sublimación de la maternidad se llevó a cabo tanto por hombres como por mujeres, como ya hemos visto. Por eso, es significativo que el semanario republicano alicantino Juventud publicara una respuesta de Hildegart ${ }^{40}$ a las declaraciones del Decano del Colegio de Abogados de Madrid, Ángel Ossorio y Gallardo -de ideología monárquica y conservadora-, ante su negativa a que las mujeres pudieran aspirar a cargos de juez, notario, oficial letrado, etc., que expresó diciendo que «después de ser mujeres, las mujeres pueden ser todo lo que quieran», a lo que Hildegart respondió:

[...] ¿cómo no se exige al hombre idéntica prueba de su virilidad, antes del ejercicio de una profesión? [...] Si la función primordial de la mujer es la maternidad, la función del hombre es, por las mismas razones alegadas para el primer postulado, la paternidad. Y si la mujer debe ser ante todo mujer, el hombre debe también ante todo demostrarlo ${ }^{41}$.

Estas declaraciones que demandaban el derecho al acceso de las mujeres a ciertos cargos profesionales, sustentadas en un principio de igualdad total entre mujeres y hombres, contrastan con las expresadas por las mujeres de tendencia conservadora que seguían reivindicando su actuación en la política en función de su supuesta naturaleza diferenciada, como hace Matilde García que, aunque veía a las mujeres capaces de gobernar, tenía ciertas reticencias ya que creía que las cualidades femeninas que por un lado ayudaban en algunos aspectos como la paz y la economía, por otro lado podían no ser tan beneficiosas:

[...] Como mujer estoy convencida de que por sus sentimentalismos, [las mujeres] sabría[n] intervenir con vehemencia de paz y perdón, que tendiera a beneficiar a la humanidad en trances de angustiosas tragedias; en el orden económico también la creo capacitada para encauzar los trabajos por caminos de arreglos amistosos que beneficiará a los más; pero hay en las naciones hondos secretos, serios compromisos que la más leve imprudencia los llevaría a una posible catástrofe [...] Yo quiero hacerme la ilusión de que [...] cuando el espíritu femenino intervenga en los Estados, sin olvidarse a sí mismo,

40. Hildegart Rodríguez militó en el Partido Socialista y en el Partido Republicano Federal. Fue cofundadora junto con Gregorio Marañón de la Liga Española para la Reforma Sexual. Intelectual precoz, a la edad de 16 años había terminado Derecho y su labor era reconocida dentro y fuera de España. Escribía en prensa, siendo colaboradora habitual de las publicaciones republicanas de izquierda en Alicante Juventud, Rebeldía, El Luchador y Lucha.

41. RODRÍGUEZ, Hildegart L. «Feminismo Nuevo», Juventud, 23-III-1930.

Feminismo/s 16, diciembre 2010, pp. 139-158 
como poder y como mujer, se dibuje en el cielo un iris de paz que ilumine con sus colores de ideales matices a la humanidad entera ${ }^{42}$.

Otra de las cuestiones que más discusiones provocó fue la cuestión del sufragio femenino, un debate que se reavivó sobre todo en dos momentos de la dictadura: con motivo de la publicación del Estatuto Municipal de 1924 y con la redacción del Anteproyecto de Constitución en 1929. Desde El Luchador, diario de tendencia republicana de izquierda, Roberto Castrovido defendió en 1924 el sufragio universal y consideró insuficiente la concesión del Directorio, aunque fuera un primer paso hacia la emancipación de las mujeres. También criticó a liberales y republicanos por sus reticencias a la aprobación del voto integral por miedo al posible voto conservador de las mujeres:

[...] para muchos liberales y no pocos republicanos el reconocer derechos políticos a la mujer es una utopía y es también una temeridad. No niegan el derecho: temen el resultado de la concesión. La mujer con su voto ha de favorecer no sólo a la Iglesia, a la monarquía, a todo conservador, sino al reaccionario. Eminencias del liberalismo han mantenido esta tesis. [...] Aunque tuvieran razón [...] defendería sus derechos políticos [de las mujeres] [...] La mujer adelantaría en política como ha adelantado en el ejercicio de profesiones que le estaban vedadas. [...] Cierto que los sexos no son iguales; pero evidente que las diferencias físicas no justifican las jurídicas y las políticas. [... La española ha pugnado más que por los derechos políticos por las modificaciones en el Código Civil. Con voto podrá más fácilmente conseguir sus justos anhelos. [...] Se otorga [el derecho de sufragio] a las mujeres viudas o solteras que sean cabezas de familia, para elegir concejales y se le reconoce el derecho de ser elegida. No es todo lo deseado; pero es algo, es el principio de una serie de reformas que emanciparán a la mujer ${ }^{43}$.

Al final de la dictadura el debate sobre el sufragio femenino volvió a cobrar fuerza con motivo del Anteproyecto Constitucional que contemplaba el voto político integral sin distinción de sexo, con la condición de haber cumplido la edad legal y gozar de la plenitud de los derechos civiles «correspondientes al estado de cada cual» (artículo 55) ${ }^{44}$. No tardaron en alzarse las voces contrarias a la aprobación de dichos derechos de las mujeres, sobre todo desde sectores republicanos de izquierda, por el miedo de que las mujeres dieran su voto a los partidos conservadores y católicos. El proceso de feminización

42. GARCíA, Matilde. «La mujer en el poder», El Tiempo, 16-XII-1927.

43. CASTROVIDO, Roberto. "La mujer del siglo XX», El Luchador, 21-III-1924.

44. La ambigüedad de esta última frase creó una polémica entre la presidenta de la ANME (Asociación Nacional de Mujeres Españolas), Benita Asas, y los redactores del Anteproyecto a través de la revista Justicia. Llegaron a la conclusión de que este artículo concedía la plenitud del voto a las mujeres a falta de la aprobación del documento. Ver DíAZ FernándeZ, Paloma. Op. cit., p.187. 
de la práctica religiosa que se dio en el siglo XIX y el miedo a la importante movilización política de las católicas sirvió de base para la formación de un estereotipo femenino que caracterizaba a las mujeres como beatas, crédulas, incultas y dominadas por el clero ${ }^{45}$, estereotipo en que se fundamentaron ciertos sectores republicanos para tomar postura en contra del sufragio femenino:

Obtener derechos políticos les sería [a las mujeres], hoy por hoy, contraproducente, representando [...] una mera entrega de votos y no la legítima expresión de la voluntad femenina [...] No hay que ser muy observador para notar el enorme influjo de la Iglesia sobre la mujer española [...] y lo sometida que esta se encuentra [...] a las decisiones de esos. [... ] Precisa [la mujer] antes de conseguir esos derechos, un medio de libertad, en el que se difunda la cultura y donde consigan una orientación sincera que [...] necesita hoy la mujer para opinar ${ }^{46}$.

Por su parte, desde la prensa socialista se defendía la igualdad de derechos entre mujeres y hombres, y se intentó atraer a las mujeres al socialismo, ya que se consideraba que era la única vía de emancipación de las mujeres que, una vez libres de la ignorancia, lucharían al lado de los hombres por la revolución social:

Comprende, mujer, cual es tu papel. [...] Piensa que una sociedad como esta no puede ser nunca justa y piensa también que tú puedes desempeñar un gran papel en el presente y en el futuro [...] Sueña con un ideal en que seas libre, en el que puedas amar a tu gusto, y crear una familia libre de pesadumbres económicas, en una sociedad en que reine la fraternidad que es el exponente del mayor cariño bien cultivado. Cuando sientas esto sin proponértelo eres socialista, y vendrás a nuestro $l_{a d o}{ }^{47}$.

Para poder traer a la mujer al socialismo, se les debe dar todos sus derechos y no considerarle menos que nosotros [...] Todos los trabajadores debemos trabajar con actividad y constancia por que desaparezca la ignorancia en la mujer, porque [...] es el mayor obstáculo que interrumpe nuestra marcha hacia el triunfo de nuestro ideal socialista ${ }^{48}$.

El Anteproyecto no llegó a aprobarse. En enero de 1930 Primo de Rivera presentó su dimisión y en febrero se disolvieron los ayuntamientos de la dictadura y la Asamblea Nacional. Se empezaron a revisar las medidas adoptadas por la dictadura y finalmente las mujeres fueron eliminadas del censo electoral,

45. Salomón ChÉliz, Ma del Pilar. Op. cit., p. 42; Blasco Herranz, Inmaculada. « Tenemos las armas de nuestra fe...», Op.cit., p. 4; ARCE PINEDO, Rebeca. «De la mujer social a la mujer azul...», Op. cit., p. 258.

46. SÁNCHEZ BohorqueZ, José Ma . «Vindicaciones femeninas», Juventud, 23-II-1930.

47. RoJo, Mariano. El Mundo Obrero, 8-II-1930.

48. MARTíneZ, Jesús. «Cómo debemos atraer las mujeres al socialismo», El Mundo Obrero, 30-XII-1928.

Feminismo/s 16, diciembre 2010, pp. 139-158 
así que no pudieron votar en las elecciones de abril de 1931. Como es de sobra conocido, tendrían que esperar a la aprobación de la Constitución republicana que establecerá el sufragio universal completo.

\section{Conclusiones}

Durante la dictadura de Primo de Rivera se dio una coincidencia entre el discurso del régimen sobre el modelo de mujer ideal y el proyecto de ciudadanía femenina elaborado por algunos grupos de mujeres, entre ellos, Acción Católica de la Mujer, que se sustentaba en una identidad de género basada en la diferencia sexual. Esto permitió una concesión limitada de derechos políticos a las mujeres que por primera vez entraron a formar parte de la vida política.

Esta circunstancia se tradujo en Alicante en la incorporación de tres concejalas al ayuntamiento y en la apertura de varios debates en la prensa sobre la conveniencia de la participación política de las mujeres y sobre su papel en la sociedad y en la familia.

Aunque la mayoría de los escritos aparecidos en la prensa alicantina, ya fueran firmados por hombres o por mujeres, defendían una participación política femenina restringida y condicionada por las cualidades características del modelo de mujer tradicional, y seguían valorando la maternidad como destino ideal de las mujeres, también hubo excepciones que demandaron una mayor igualdad y derechos políticos completos para las mujeres, opiniones más trasgresoras que defendieron una ciudadanía femenina en condiciones de igualdad con respecto a la masculina, y que se alejaban del discurso de la complementariedad de los sexos.

El régimen primorriverista permitió por primera vez la participación de las mujeres en la política activa. Y aunque ésta se produjo en un contexto en el que los derechos políticos y sociales estaban muy limitados, esta primera toma de contacto sentó las bases para una movilización femenina que alzó el vuelo en los años treinta. Sin embargo, la representación simbólica de este poder que por primera vez era ejercido por las mujeres se nutría del modelo de feminidad que entendía que las mujeres poseían ciertas características diferentes a las de los hombres, características que determinaban qué funciones podían desempeñar. Así, de forma mayoritaria, se interpretó el trabajo de las mujeres en los municipios como una extensión de las cualidades femeninas al espacio público. Por lo que la imagen del poder de estas mujeres era, en general, una proyección de la figura de la mujer de la familia al ayuntamiento. 


\section{Referencias bibliográficas}

Aguado, Ana. «Ciudadanía, mujeres y democracia». Historia Constitucional, 6 (2005), pp. 11-27.

ARCE PinEDO, Rebeca. «De la mujer social a la mujer azul: la reconstrucción de la feminidad por las derechas españolas durante el primer tercio del siglo XX». Ayer, 57 (2005), pp. 247-272.

- Dios, patria y hogar. La construcción social de la mujer española por el catolicismo y las derechas en el primer tercio del siglo XX. Santander, PubliCan, Ediciones de la Universidad de Cantabria, 2007.

ARESTI, Nerea. Médicos, donjuanes y mujeres modernas. Los ideales de feminidad y masculinidad en el primer tercio del siglo XX. Bilbao, Servicio Editorial de la Universidad del País Vasco, 2001.

Blasco Herranz, Inmaculada. « Tenemos las armas de nuestra fe y de nuestro amor y patriotismo; pero nos falta algo'. La Acción Católica de la Mujer y la participación política en la España del primer tercio del siglo XX». Historia Social, 44 (2002), pp. 3-20.

- Paradojas de la ortodoxia. Políticas de masas y militancia católica en España (1919-1939). Zaragoza, Prensas Universitarias de Zaragoza, 2003.

- «Ciudadanía y militancia católica femenina en la España de los años veinte». Ayer, 57 (2005), pp. 223-246.

CAPEL, Rosa María: «El modelo de mujer en España a comienzos del siglo XX». En V. Maquieira D’Angelo, G. Gómez-Ferrer Morant y M. Ortega López (eds.). Mujeres y hombres en la formación del Pensamiento Occidental. Actas de las VII Jornadas de Investigación Interdisciplinaria. Madrid, Instituto Universitario de Estudios de la Mujer, Universidad Autónoma de Madrid, 1989, vol. II, pp. 311-320.

DíAz FERnÁndeZ, Paloma. «La dictadura de Primo de Rivera. Una oportunidad para la mujer». Espacio, Tiempo y Forma, Serie V, $H^{a}$ Contemporánea, 17 (2005), pp. 175-190.

FAgOAGA, Concha. La voz y el voto de las mujeres. El sufragismo en España. 18771931. Barcelona, Icaria, 1985.

FOlGuera CRESPO, Pilar: «Feminismo y Estado: la participación de la mujer en las instituciones políticas durante la dictadura de Primo de Rivera». Bulletin du Département de Recherches Hispaniques Pyrenaica, 27 (1983), pp. 32-51.

- «Revolución y Restauración. La emergencia de los primeros ideales emancipadores (1868-1931)». En E. Garrido (ed.). Historia de las mujeres en España. Madrid, Síntesis, 1997, pp. 451-492.

FRAISSE, Geneviève. Los dos gobiernos: la familia y la ciudad. Madrid, Cátedra (Feminismos), 2003. 
FRANCO RUBIO, Gloria Ángeles. «La contribución de la mujer española a la política contemporánea: de la Restauración a la Guerra Civil (1876-1939)». En R.M. Capel Martínez (coord.). Mujer y sociedad en España (1700-1975). Madrid, Ministerio de Cultura, Instituto de la Mujer, 1986, pp. 239-263.

- «Los orígenes del sufragismo en España». Espacio, Tiempo y Forma, Serie V, 16 (2004), pp. 455-482.

GÓMEZ-FERRER, Guadalupe. «Hacia una redefinición de la identidad femenina: las primeras décadas del siglo XX». Cuadernos de Historia Contemporánea, 24 (2004), pp. 9-22.

GonZÁlez CASTILlejo, Mª José: «Entre lo público y lo privado: mujeres y ciudadanía durante la Dictadura de Primo de Rivera». En C. Campos Luque y M.J. González Castillejo (coords.). Mujeres y dictaduras en Europa y América: el largo camino. Málaga, Universidad de Málaga, 1996, pp. 49-74.

Moreno SÁEz, Francisco (ed.). La prensa en la ciudad de Alicante durante la dictadura de Primo de Rivera (1923-1931). Alicante, Instituto de Cultura «Juan Gil-Albert», Diputación Provincial de Alicante, 1995.

NASH, Mary. Mujeres en el mundo. Historia, retos y movimientos. Madrid, Alianza, 2004.

- «Identidades de género, mecanismos de subalternidad y procesos de emancipación femenina». Revista CIDOB d'Afers Internacionals, 73-74 (2006), pp. 39-57.

NiELFA, Gloria et alii. «El acceso de las mujeres a los poderes locales en España». $X$ Congreso de la Asociación de Historia Contemporánea, Universidad de Cantabria, 2010 (en prensa).

SAlOMÓn CHÉliz, Ma del Pilar. «Beatas sojuzgadas por el clero: la imagen de las mujeres en el discurso anticlerical en la España del primer tercio del siglo XX». Feminismo/s, 2 (2003), pp. 41-58. 